\title{
Heavy mineral composition and granulometry characteristic of current sediments of Vjosa River Delta Littoral (Albania)
}

\author{
Emiriana Xhaferri ${ }^{1}$, Agim Sinojmeri ${ }^{2}$, Çerçis Durmishi ${ }^{2}$, Leonard Alimeta ${ }^{3}$, \\ ${ }^{1}$ PhD Student, Polytechnic University of Tirana, Albania \\ ${ }^{2}$ Faculty of Geology and Mining, Polytechnic University of Tirana, Albania \\ ${ }^{3}$ ABIESSE, Albania
}

\begin{abstract}
For the determination of the heavy minerals composition of the Vjosa River Delta deposits and characterization of the granulometry of samples taken in littoral, X-ray Diffractometry technique and Laser Diffraction Analysis (LDA) were used. The Vjosa River delta stretches from Hoxhara channel, at the north, to molasses hills of Zvërnec in the south, forming a littoral of about $22 \mathrm{~km}$. Two old river mouth are identified, one in the south, near to Narta lagoon, and one in the north of the actual delta, which is related to the position of current Hoxhara artificial channel. Related to the hydraulic elaboration of shoreline sediments, several layers of heavy mineral deposits, up to $50 \mathrm{~cm}$ thick, with heavy mineral fraction up to $90 \%$ of total sample are identified. XRD analysis reveals a large variety of heavy minerals present in these sediments. Chromite and magnetite are the main components of the heavy fraction. Occasionally, accumulations of garnets (up to 13.6\%), zircon (up to 2\%), rutile (up to $3.8 \%$ ) and ilmenite (up to $3.8 \%$ ) are also observed. Rock forming minerals as pyroxenes, amphibole, olivine and epidote compose the rest of the samples. LDA analyses indicate that Vjosa delta sediments consist on fine to medium granulometry, well sorted to moderately well sorted sands, symmetrical to fine skewness, with mesokurtosis to very leptokurtic distribution.
\end{abstract}

Keywords: Enrichment, Granulometry, Heavy Mineral, Laser Diffraction Analysis, XRD 